\title{
Annemarieke Willemsen, Back to the Schoolyard. The Daily Practice of Medieval and Renaissance Education
}

\section{G. Matteo Roccati}

\section{(2) OpenEdition}

\section{Journals}

Édition électronique

URL : http://journals.openedition.org/studifrancesi/5514

DOI : 10.4000/studifrancesi.5514

ISSN : 2427-5856

Éditeur

Rosenberg \& Sellier

\section{Édition imprimée}

Date de publication : 1 septembre 2011

Pagination : 381

ISSN : 0039-2944

\section{Référence électronique}

G. Matteo Roccati, « Annemarieke Willemsen, Back to the Schoolyard. The Daily Practice of Medieval and Renaissance Education », Studi Francesi [En ligne], 164 (LV | II) | 2011, mis en ligne le 30 novembre 2015, consulté le 09 janvier 2021. URL : http://journals.openedition.org/studifrancesi/5514 ; DOI : https:// doi.org/10.4000/studifrancesi.5514

Ce document a été généré automatiquement le 9 janvier 2021.

\section{(c) $($ ) $\odot$ (8)}

Studi Francesi è distribuita con Licenza Creative Commons Attribuzione - Non commerciale - Non opere derivate 4.0 Internazionale. 


\title{
Annemarieke Willemsen, Back to the Schoolyard. The Daily Practice of Medieval and Renaissance Education
}

\author{
G. Matteo Roccati
}

\section{RÉFÉRENCE}

ANNEMARIEKE WILLEMSEN, Back to the Schoolyard. The Daily Practice of Medieval and Renaissance Education, Turnhout, Brepols, 2008 («Studies in European Urban History (1100-1800)», 15), 324 pp.

1 L'étude est axée sur les Pays Bas (confrontés avec d'autres pays d'Europe, en particulier l'Italie), mais a un intérêt plus large car elle constitue une bonne présentation des aspects concrets de la vie scolaire entre 1300 et 1600 (systèmes d'enseignement, aspects matériels, vie quotidienne). L'ouvrage s'appuie sur des sources écrites et iconographiques, ainsi que sur des découvertes archéologiques, et comporte de nombreuses illustrations (objets, représentations de la réalité scolaire). 